Mean (SEM) maternal and fetal circulatory variables before and 15 and 30 minutes after epidural analgesia $(n=6)$

\begin{tabular}{lccc}
\hline & $\begin{array}{c}\text { Control } \\
\text { period }\end{array}$ & $\begin{array}{c}15 \text { minutes } \\
\text { after }\end{array}$ & $\begin{array}{c}30 \text { minutes } \\
\text { after }\end{array}$ \\
\hline \multicolumn{4}{c}{ Maternal variables } \\
Systolic blood pressure (mm Hg) & $113(1 \cdot 7)$ & $108(3 \cdot 1)$ & $107(2 \cdot 5)$ \\
$\begin{array}{l}\text { Diastolic blood pressure (mm Hg) } \\
\text { Heart rate (beats/min) }\end{array}$ & $68(1 \cdot 7)$ & $56(3 \cdot)$ & $53(4 \cdot 2)$ \\
& $69(6 \cdot 1)$ & $75(4 \cdot 2)$ & $77(3 \cdot 1)$ \\
Heart rate (beats/min) & Fetal variables & & \\
Aortic pulsatility index & $125(1 \cdot 8)$ & $131(3.5)$ & $126(3 \cdot 4)$ \\
& $2 \cdot 1(0 \cdot 2)$ & $1 \cdot 9(0 \cdot 2)$ & $1 \cdot 9(0 \cdot 1)$ \\
\hline
\end{tabular}
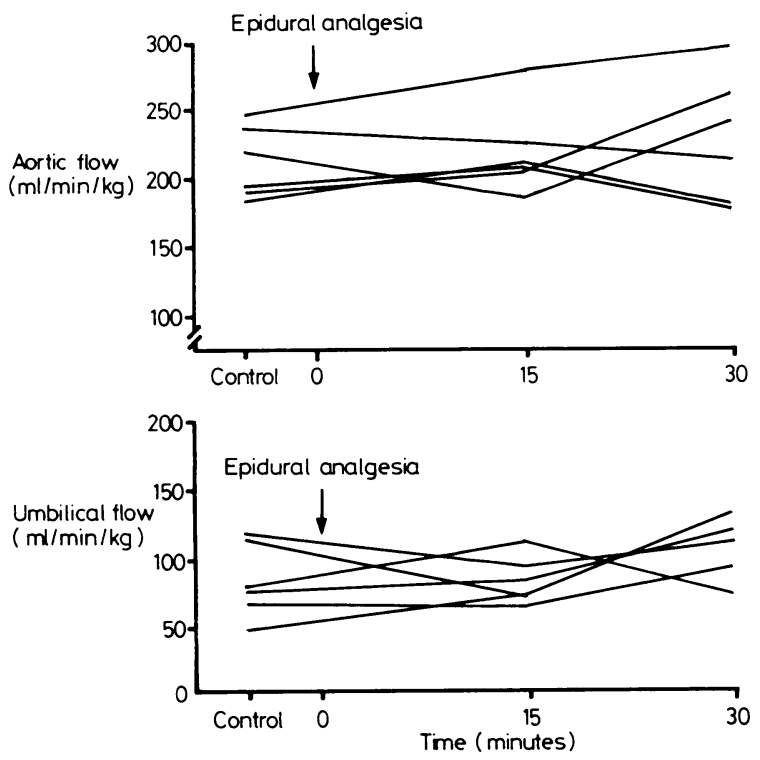

Fetal aortic and umbilical blood flow before and after epidural analgesia in six pregnancies. (One measurement of umbilical flow at 30 minutes is missing for technical reasons.)

\section{Discussion}

Local anaesthetics used for obstetric analgesia exert a direct negative inotropic effect on the fetal heart in in vitro experiments. ${ }^{4}$ The possible effects on fetal circulation in utero could previously be evaluated only by monitoring fetal heart rate or indirectly by assessing the condition of the newborn infant. The non-invasive method of measuring fetal blood flow used in the present study can detect changes in fetal cardiac output, as has been shown in fetuses with cardiac arrhythmias. ${ }^{5}$ In the present, preliminary report none of the fetal circulatory variables changed appreciably after the induction of epidural analgesia. These results indicate that epidural analgesia with etidocaine and bupivacaine does not affect the fetal circulation in normotensive mothers.

This ultrasonic method of measuring fetal blood flow provides a useful means of studying the influence of anaesthetic drugs or techniques, or both, on fetal circulation and can thereby help to make obstetric analgesia safer.

This study was supported by the Swedish Medical Research Council (grant No B84-17X-05980-04).

\section{References}

1 Jouppila R, Jouppila P, Hollmén A, et al. Effect of the anesthetic method, epidural and general anesthesia, on intervillous blood flow in cesarean sections. Regional Anesthesie 1977;2:2-8.

${ }^{2}$ Eik-Nes SH, Brubakk AD, U'stein MK. Measurement of human fetal blood flow. Br Med f 1980;280:283-4.

${ }^{3}$ McCallum WD. Fetal cardiac anatomy and vascular dynamics. Clin Obstet Gynecol $1981 ; 24: 837-49$.

4 Andersson KE, Gennser G, Nilsson E. Influence of mepivacaine on isolated human foetal hearts at normal and low pH. Acta Physiol Scand 1970;80, suppl 353:34-47.

${ }^{5}$ Maršál K, Eik-Nes SH, Lindblad A, Lingman G. Blood flow in the fetal descending aorta; intrinsic factors affecting fetal blood flow-that is, fetal breathing movements and cardiac arrhythmia. Ultrasound Med Biol (in press).

(Accepted 14 February 1984)

\title{
Bleeding oesophageal varices and hepatic dysfunction in adult polycystic kidney disease
}

\author{
P J RATCLIFFE，S REEDERS，J M THEAKER
}

\begin{abstract}
A patient with adult polycystic liver and kidney disease presented with haematemesis and melaena and was found to have raised serum creatinine, aspartate transaminase, and alkaline phosphatase values; hypoalbu-
\end{abstract}

John Radcliffe Hospital, Oxford OX3 9DU

P J RATCLIFFE, MRCP, medical registrar

$J$ M THEAKER, MA, MB, registrar in pathology

Renal Unit, Churchill Hospital, Oxford

$S$ REEDERS, MRCP, registrar

Correspondence to: Dr P J Ratcliffe. minaemia; and a prolonged prothrombin ratio. She also had oesophageal varices. With haemodialysis her aspartate transaminase activity fell to normal but she remained hypoalbuminaemic with a prolonged prothrombin ratio. She died after three weeks.

Although hepatic cysts do occur in adult polycystic kidney disease, they have been thought not to cause major liver disease. The hepatic cysts in this patient, however, did appear to be associated with portal hypertension and impaired hepatocellular function.

\section{Introduction}

A patient with autosomal dominant adult polycystic kidney disease had severe hepatic cystic disease associated with portal hypertension and hepatocellular dysfunction. Unusually extensive cystic hepatic disease was also seen in her daughter, who at the time had normal renal function. 


\section{Case report}

A 51 year old woman had been noted to have massive hepatomegaly at an employment medical examination 17 years earlier. Sixteen years later she was found to be anaemic. Blood pressure was $150 / 100 \mathrm{~mm} \mathrm{Hg}$ and her abdomen was distended by an enlarged liver and kidneys. Serum creatinine concentration was $597 \mu \mathrm{mol} / 1(6.75 \mathrm{mg} / 100 \mathrm{ml})$, serum bilirubin concentration and aspartate transaminase activity normal, and serum albumin $43 \mathrm{~g} / \mathrm{l}$. Ultrasonography showed polycystic liver and kidneys. A year after this she was admitted to hospital with haematemesis and melaena. She had developed ascites. Laboratory investigations showed: haemoglobin $6.8 \mathrm{~g} / \mathrm{dl}$; serum creatinine $790 \mu \mathrm{mol} / 1(8.9 \mathrm{mg} / 100 \mathrm{ml})$; serum bilirubin normal; serum aspartate transaminase $179 \mathrm{IU} / 1$ (normal 5-35 IU/1); serum alkaline phosphatase $434 \mathrm{IU} / 1$ (normal 50-300 IU/1); serum albumin $31 \mathrm{~g} / 1$; and prothrombin ratio $2 \cdot 3: 1$. An ascitic tap showed a clear transudate.

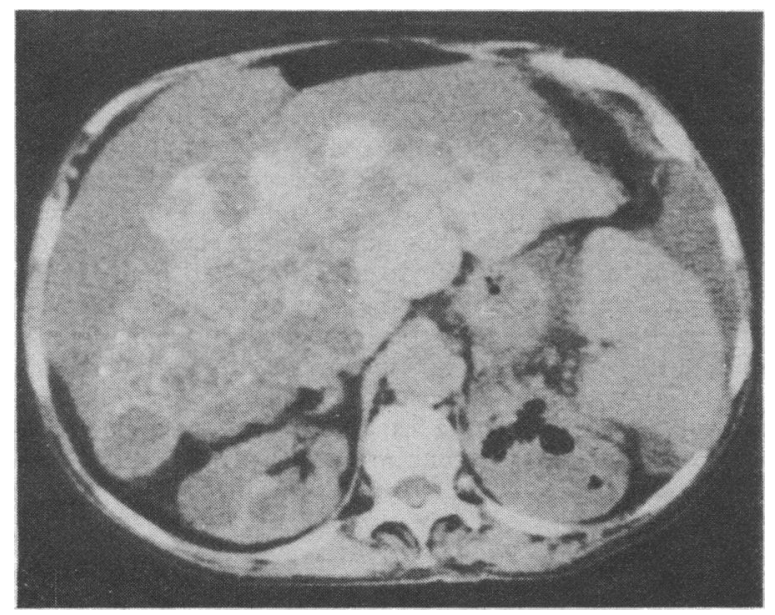

FIG 1-The patient's liver has been largely replaced by multiple low density cysts, some of which show peripheral calcification. A large quantity of ascites lies anterior to the liver. The spleen is enlarged. The kidneys are also cystic.

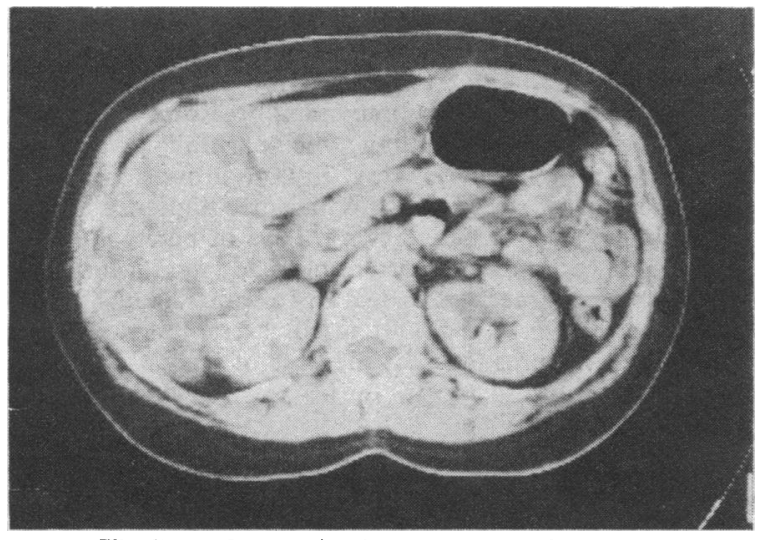

FIG 2-The liver of the patient's daughter is enlarged by multiple low density cysts. A few cysts are also seen in the kidneys.

Endoscopy showed oesophageal varices. There was no history of ethanol or drug ingestion. Tests for various viruses, including hepatitis B antigen, gave negative results. Computed tomography showed a calcified cystic liver, splenomegaly, and ascites (fig 1). Haemodialysis was started, and the serum aspartate transaminase activity fell to 20-30 IU/1, but her serum albumin concentration remained low and the prothrombin ratio was prolonged at 1·7:1. Three weeks later she sustained a hemiparesis and died.

Necropsy showed that the liver $(2000 \mathrm{~g})$ had been mostly replaced by cysts with intervening fibrous tissue. The remaining hepatic parenchyma was of normal architecture but showed mild fatty change, some loss of centrilobular hepatocytes, and slight fibrosis around terminal hepatic vein radicles. The spleen was enlarged $(320 \mathrm{~g})$ and the portal vein dilated and patent. The kidneys had the typical appearance of adult polycystic kidney disease.

The patient's only daughter, aged 40 , was also found to have massive hepatomegaly. Her serum creatinine concentration was normal. Computed tomography showed a large polycystic liver with some small cysts in the kidneys (fig 2). The patient's father had died at the age of $\mathbf{4 8}$ from kidney disease of unknown type.

\section{Discussion}

Hepatic disease is seen in both infantile and adult polycystic kidney disease. In the infantile form portal hypertension is common and related to progressive hepatic fibrosis. In adult polycystic disease the intervening hepatic parenchyma is normal. This distinction is complicated by the existence of adult polycystic kidney disease associated with congenital hepatic fibrosis, but in such cases the renal lesion may have been wrongly diagnosed; it has been suggested that in long term survivors of the infantile form of polycystic kidney disease the final stages of ectasia of the collecting tubules mimic the adult form of the disease. ${ }^{1}$ In our patient we saw no diffuse hepatic fibrosis, the histological appearances were typical of adult polycystic kidney disease, and inheritance was dominant. Within families with adult polycystic kidney disease there is a tendency to breed true for the severity of renal disease. In this family this tendency was displayed for the extent of hepatic disease.

Surveys of adult polycystic kidney disease have shown that $30-50 \%$ of patients have hepatic cysts. ${ }^{2} 3$ Liver function in these patients was normal, which has led to the suggestion that the hepatic cysts never cause appreciable liver disease. The few reports of oesophageal varices in adult polycystic kidney disease $^{4} 5$ have been challenged on the grounds that a family history or detailed pathological description has been lacking and that therefore another disease might have been responsible for the portal hypertension. ${ }^{3}$

Our patient had portal hypertension, and hepatocellular dysfunction was reflected by a prolonged prothrombin time and hypoalbuminaemia. This was apparently due to the replacement of most of the hepatic parenchyma by cysts. Compression of the portal vein by cysts may have contributed to portal hypertension, and compression of the hepatic veins by cysts may have been responsible for the slight centrilobular changes. We have reported this case to show that cystic lesions of the liver in adult polycystic kidney disease may occasionally lead to impairment of hepatocellular function and portal hypertension.

We are grateful to Professor D J Weatherall and Dr D O Oliver for permission to report this case and to Dr S Golding, who obtained the computed tomographic images.

\section{References}

1 Dupond J-L, Miguet J-P, Carbillet J-P, Saint-Hillier Y, Perol C, LeContedes-Floris $\mathbf{R}$. Kidney polycystic disease in adult congenital hepatic fibrosis. Ann Intern Med 1978;88:514-5.

${ }^{2}$ Oreopoulos DG, Bell TK, McGeown MG. Liver function and the liver scan in patients with polycystic kidney disease. Br $\mathcal{F}$ Urol 1971 ;43:273-6.

${ }^{3}$ Milutinovic J, Fialkow PJ, Rudd TG, Agodoa LY, Phillips LA, Bryant JI. Liver cysts in patier:s with autosomal dominant polycystic kidney disease. $A m$ F Med 1980;68:741-4.

- Katzen NG. Fatal hepatic polycystic disease. Br Med F 1964;i:839-40.

5 DelGuercio E, Greco J, Kim KE, Chinitz J, Swartz C. Esophageal varices in adult patients with polycystic kidney and liver disease. $N$ Engl f Med $1973 ; 289: 678-9$.

(Accepted 14 February 1984) 